New techniques

\title{
Nasal ventilation
}

\author{
Anita K Simonds
}

\begin{abstract}
Summary
Nasal intermittent positive pressure ventilation is likely to have an increasing role in the management of acute ventilatory failure, weaning, and chronic ventilatory problems. Further improvements in ventilator and mask design will be seen. Appropriate application is likely to reduce both mortality and admissions to intensive care, while domiciliary use can improve life expectancy and/or quality of life in chronic ventilatory disorders. As with any new technique, enthusiasm should not outweigh clear outcome information, and possible new indications should always be subject to careful assessment.
\end{abstract}

Keywords: nasal intermittent positive pressure ventilation; ventilation

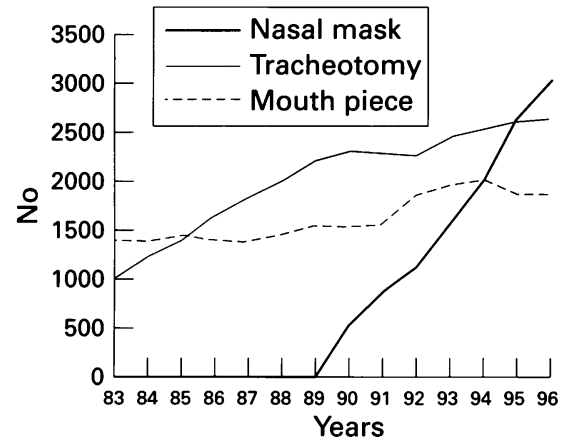

Figure 1 Trends in use of ventilatory modes in France, 1983-96 (from Antadir database)

\section{Technical aspects}

The realisation that artificial ventilation can be delivered noninvasively using a mask is not new. First-aid kits placed by the Royal Humane Society in houses along the banks of the Thames and coastal regions in the $1770 \mathrm{~s}$, included a set of nasal masks for the resuscitation of victims of drowning accidents. However, widespread use of mask respiratory support in intensive care and highdependency units, and in acute medical wards, has only occurred in recent years. Improvements in facemask design were stimulated by the increasing use of continuous positive airway pressure (CPAP) in acute respiratory failure due to severe pneumonia and pulmonary oedema, and the crucial recognition that CPAP is effective therapy for obstructive sleep apnoea in $1981 . .^{1}$ Subsequently portable ventilators designed for domiciliary application in patients with obstructive sleep apnoea or hypoventilation syndromes have crossed back into acute use for hospital treatment of decompensated respiratory failure. Expansion of the use of nasal intermittent positive pressure ventilation (NIPPV) in Europe and the US has been dramatic, with NIPPV overtaking other forms of noninvasive ventilatory support. There are no accurate UK or US figures of NIPPV uptake, but data collection is complete in France and trends as shown in figure $1^{2}$ are likely to be reflected elsewhere.

\section{VENTILATORS}

Currently the most popular all-purpose mode of nasal ventilation is bilevel pressure support using equipment such as BiPAP (Respironics Inc), VPAP (Resmed), Puritan Bennett and Breas models. Here, inspiratory positive airway pressure (IPAP) and expiratory positive airway pressure (EPAP) levels are set and the ventilators can be used in assist-control (spontaneous/timed) or triggered modes alone (spontaneous). Occasionally, the controlled (timed) mode is used. These pressure-support ventilators are generally robust, portable, and user-friendly, enabling patients to be ventilated outside the intensive care unit environment or in the home. Other pressure-preset ventilators, such as the NIPPY (Friday Medical), are also popular.

Volume-preset ventilators have a longer clinical track record than their pressure-preset counterparts and are extensively used in some units in Europe and the US. In many clinical situations there is no particular advantage to any one type of ventilator. ${ }^{3}$ However, in some cases, eg, bullous lung disease or pneumothorax, pressure-preset ventilators may be advantageous, while volumepreset ventilators may be better at meeting ventilatory needs in patients with labile airway resistance and fluctuating lung compliance. In practice, factors such as convenience and patient preference are important once optimal arterial blood gas control has been achieved.

The newest mode of noninvasive ventilation is proportional assist ventilation (PAV),${ }^{45}$ in which ventilatory assistance is provided in proportion to the patient's ventilatory demands. This mode is currently being evaluated and it is not clear yet whether PAV offers any advantages over pressure support. Special attention is required to assess the role of PAV during sleep, as nocturnal hypoventilation may not be adequately controlled.

Smaller ventilators are also being developed. The prototype Hippy ventilator (Friday Medical) is battery-powered and designed to aid ventilation in ambulatory patients. By necessity, these smaller inspiratory support ventilators are less powerful and some do not have a breath-triggering capability. The role of portable ventilators as a rehabilitation aid in chronic ventilatory insufficiency is also being assessed.

INTERFACES (FIGURE 2)

Positive pressure ventilation can be delivered using nasal masks, facemasks, nasal plugs or a mouthpiece. These are best matched to individual requirements and comfort, as there is no evidence that any one version of mask is more effective. However, for confused patients, mouth breathers and young children, a
Royal Brompton Hospital, Sydney

Street, London SW3 6NP, UK

A K Simonds

Accepted 19 November 1997 


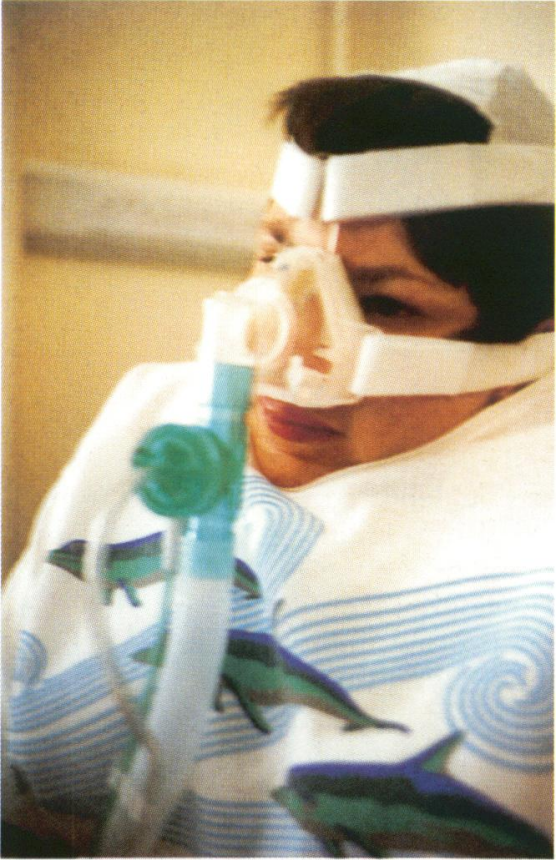

Figure 2 Nasal intermittent positive pressure ventilation in restrictive chest wall disease due to Klippel Feil syndrome

\begin{tabular}{|l|}
\hline Indications for NIPPV \\
\hline Acute \\
acute hypercapnic exacerbations of \\
COPD, chest wall disorders, \\
neuromuscular disease or \\
hypoventilation syndromes \\
- to help some patients with hypercapnia \\
secondary to bronchiectasis/cystic \\
fibrosis. \\
as an aid to weaning from \\
conventional ventilation \\
Chronic \\
home ventilation in patients with \\
neuromuscular and chest wall \\
disorders and selected patients with \\
COPD
\end{tabular}

Box 1

\begin{tabular}{|l|}
\hline Contra-indications to NIPPV \\
\hline moderate to severe bulbar weakness \\
- coma \\
- hevere confusional state \\
- naemodynamic instability \\
precluding the use of a mask. \\
\hline
\end{tabular}

Box 2
Table Overview of trials of NIPPV in acute exacerbations of COPD

\begin{tabular}{llllllllll}
\hline Ref & Study & $n$ & Entry $\mathrm{pH}$ & $\begin{array}{l}\text { Entry } \\
p C O_{2}\end{array}$ & $\begin{array}{l}\text { Time NIV } \\
(h)\end{array}$ & $\begin{array}{l}\text { Post } \\
p H\end{array}$ & $\begin{array}{l}\text { Post } \\
p C O 2\end{array}$ & Vent & $\begin{array}{l}\text { Success } \\
\text { rate }(\%)\end{array}$ \\
\hline 36 & open & 18 & 7.29 & 9.5 & 25 & 7.37 & 7.2 & P/F & 72 \\
37 & open & 13 & 7.25 & 11.4 & 69 & 7.40 & 7.5 & V/F & 77 \\
& & 16 & 7.29 & 10.1 & 57 & 7.35 & 8.0 & P/F & 87 \\
38 & open & 14 & 7.19 & 12.1 & 8 & 7.31 & 8.8 & P/F & 79 \\
39 & retrospective & 13 & 7.29 & 8.5 & 7.6 & 7.4 & 6.3 & P/F & 76 \\
9 & RCT & 60 & 7.348 & 8.6 & 7.6 & 7.376 & 7.3 & V/N & 83 \\
7 & RCT & 31 & 7.27 & 10.7 & 14.4 & $\star$ & 8.9 & P/N & 91 \\
6 & RCT & 85 & 7.27 & 9.3 & $>6$ & 7.31 & 9.1 & P/F & 74 \\
10 & RCT & 24 & 7.33 & 7.9 & $2 \times 3$ h for 3 & 7.37 & 7.2 & P/N & ND \\
& & & & & days & & & &
\end{tabular}

RCT: randomised controlled trial; $n$ : number of subjects; Vent: ventilator; V: volume preset; P: pressure preset; $M$ : mask; N: nasal mask; F: facemask; Time NIV: duration of NIPPV; ND: no difference

facemask is usually the interface of choice. For long-term use in adults, nasal masks or plugs may be preferable. The latter may be helpful in spectacle wearers, although spectacles can be modified to accommodate a mask. Customised masks can also be constructed for patients who cannot be adequately fitted with commercial models.

\section{The use of NIPPV}

The acute and chronic conditions in which NIPPV may be indicated are given in box 1 , and contraindications to NIPPV are listed in box 2 .

\section{ACUTE RESPIRATORY FAILURE}

Exacerbations of chronic obstructive pulmonary disease (COPD)

In addition to a profusion of anecdotal reports there are now four randomised controlled trials of NIPPV compared to standard management in acute hypercapnic COPD. Details of some of these studies are outlined in the table.

The largest trial by Brochard et at $(n=87)$ showed a significant reduction in mortality and the need for intubation in patients receiving NIPPV. Morbidity and mortality were strongly related to complications associated with intubation. Kramer et al have also shown that NIPPV decreases the need for intubation and that physiological indices improve more rapidly. A significant increase in $\mathrm{pH}$ and fall in $\mathrm{PaCO}_{2}$ within the first few hours of NIPPV are reliable predictors of a successful outcome. ${ }^{8}$

An earlier multicentre UK study ${ }^{9}$ showed a reduction in mortality in the NIPPV group when data were analysed by treatment efficacy. However, using an intention-to-treat analysis, there was no difference in mortality. Both $\mathrm{pH}$ and $\mathrm{PaCO}_{2}$ improved significantly after one hour of NIPPV.

The single randomised controlled study with negative results is that of Barbe et $a l,{ }^{10}$ in which patients receiving standard therapy had a similar outcome to those treated with NIPPV. This study had only 24 patients, and an unusually high number of recipients had problems tolerating NIPPV. The results suggest that, with a mean $\mathrm{pH}$ of 7.33 on entry, the patients were not as sick as those in the Brochard study ( $\mathrm{pH}$ 7.27). A reasonable conclusion is that early use of NIPPV is indicated in COPD patients with a $\mathrm{pH}$ of $<7.35$ who are failing to respond to conventional measures. In those with less severe exacerbations, NIPPV is unlikely to offer benefit over and above standard management.

\section{Restrictive ventilatory disorders}

A minority of patients with conditions other than COPD were included in the randomised controlled study of Kramer et al. ${ }^{7}$ This heterogenous group also showed a reduction in the need for intubation. Good results have been reported in patients with neuromuscular disease and chest wall disorders. ${ }^{11}{ }^{12}$ There are no randomised controlled data in these groups, but physiological considerations would suggest the outcome with NIPPV is likely to be better in patients with pure ventilatory pump failure than in those with chronic airway and/or parenchymal lung disease. NIPPV should be actively considered in acute ventilatory failure in restrictive ventilatory disorders providing that bulbar function is not severely impaired. NIPPV is also useful to control symptoms in some patients with progressive neuromuscular disease such as motor neurone disease $\mathrm{e}^{1314}$ and Duchenne muscular dystrophy..$^{15}$ In both groups, anticipation of ventilatory failure is possible and individuals should be carefully monitored once vital capacity falls below $50 \%$ predicted, as ventilatory failure is almost 


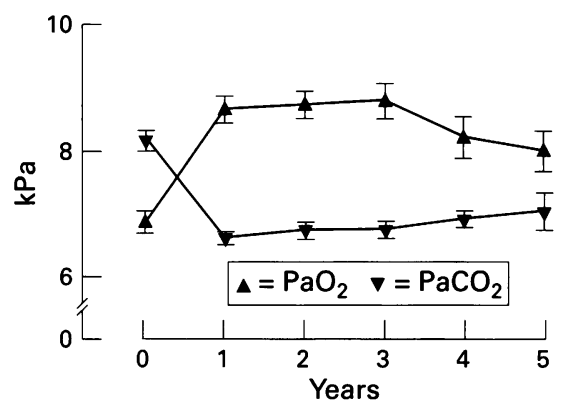

Figure 3 Arterial blood gas tensions before and after treatment with NIPPV in patients with restrictive chest wall and neuromuscular disease inevitable once vital capacity is less than $30 \%$ predicted. It should be remembered that, whereas COPD patients may exist in steady state for years with a mild to moderate degree of hypercapnia, even a minor elevation of $\mathrm{PaCO}_{2}$ in a patient with motor neurone disease suggests imminent ventilatory decompensation. In individuals with early respiratory muscle involvement, life expectancy is increased by NIPPV, whereas in those with bulbar disease or quadriplegia with late respiratory muscle involvement, NIPPV may not be appropriate.

\section{Other conditions}

Meduri et $a l^{16}$ have used NIPPV in a series of 17 cases of status asthmaticus (mean $\mathrm{pH} 7.25, \mathrm{PaCO}_{2} 8.7 \mathrm{kPa}$ ). Pressure support mode was used with the addition of $4 \mathrm{cmH}_{2} \mathrm{O}$ EPAP to offset intrinsic positive end expiratory pressure (PEEPi). Eight patients in the series had experienced previous episodes of acute ventilatory failure due to asthma. NIPPV was well tolerated and successful in all but two patients who required intubation for worsening $\mathrm{CO}_{2}$ retention. All patients survived and no ventilatory complications were seen. The average duration of NIPPV was 16 hours. These results are interesting but require confirmation by randomised controlled study. In the meantime, intubation and conventional ventilation remain the treatment of choice in status asthmaticus, but NIPPV may be indicated in less severe cases.

Cystic fibrosis

Cystic fibrosis patients may become hypercapnic during an infective exacerbation or as part of an endstage decline. Acute courses of NIPPV may hasten recovery from infective episodes ${ }^{17}$ or can be used to facilitate 'bridging' to transplantation in severely hypercapnic patients waiting for heart-lung transplantation. ${ }^{18} 19$

Implementation of NIPPV by the team

Of the randomised controlled trials listed in the table, two were carried out in intensive care units ${ }^{67}$ and two on medical wards. ${ }^{9}{ }^{10}$ Extrapolation of intensive care unit results to general ward practice should be viewed with caution, in particular as the nurse/patient ratio is inevitably reduced, and facilities for intubation should NIPPV fail, are not always ideal. For these reasons and for training purposes, NIPPV may be best carried in a high-dependency unit, if facilities are available. It has been suggested that the management of NIPPV is time-consuming for nursing and paramedical staff. ${ }^{20} \mathrm{~A}$ recent study ${ }^{21}$ contradicts this belief, showing that overall nursing time is not increased compared to conventional management, although it is possible that the NIPPV patients need more attention during the first hour of therapy. It essential that all team members, including medical trainees, physiotherapists and paramedical staff, are familiar with the technique and equipment. Regular 'hands-on' training sessions are helpful to update staff and introduce new members of the team to the technique. Most units find that one of two types of ventilator will see them through nearly all acute situations, but a variety of masks is essential to match widely differing interface needs.

\section{DOMICILIARY NIPPV FOR CHRONIC VENTILATORY FAILURE}

\section{Restrictive ventilatory disorders}

The majority of patients requiring home ventilatory support for chronic ventilatory failure can be managed with nocturnal ventilatory assistance to correct arterial blood gas disturbances during sleep. NIPPV has now overtaken negative pressure ventilation as the method of choice in this group.

A single-centre outcome study of 180 NIPPV users carried out in the $\mathrm{UK}^{22}$ has shown a 5-year survival of $79 \%$ in scoliosis patients, $94 \%$ for those with old tuberculous lung disease, $100 \%$ for post-polio patients, and $43 \%$ in COPD. Similar results were seen in a large French multicentre study. ${ }^{23}$ Daytime arterial blood gas tensions are significantly improved (figure 3), and SF-36 quality of life scores are similar to individuals with other chronic disorders such as diabetes mellitus or ischaemic heart disease. ${ }^{22}$ Significant falls in pulmonary hypertension have been seen in some groups. ${ }^{24}$ Many patients were able to return to full time work or higher education. More recently, 5-year survival has been demonstrated to be as high as $73 \%$ in Duchenne muscular dystrophy. ${ }^{25}$

\section{COPD}

Hypercapnia was shown to be an adverse prognostic factor in the MRC study of long-term oxygen therapy (LTOT) in COPD. ${ }^{26}$ Assisted ventilation is therefore of potential relevance in this group, particularly for patients who fail LTOT because of progressive hypercapnia. Mixed results were achieved in early uncontrolled studies of NIPPV in COPD, ${ }^{27}{ }^{28}$ although NIPPV appears to be more mechanically effective than negative pressure ventilation. ${ }^{29}$ 
A recent cross-over study ${ }^{30}$ of LTOT versus NIPPV-plus-LTOT produced improvements in $\mathrm{PaO}_{2}, \mathrm{PaCO}_{2}$ and quality-of-life indices in the NIPPV group. In contrast, a trial ${ }^{31}$ in which COPD patients were randomised to a sham treatment group (effectively $2 \mathrm{cmH}_{2} \mathrm{O}$ EPAP) or active NIPPV, showed no improvements in nocturnal or diurnal arterial blood gas tensions in the NIPPV group. However, maximal IPAP levels in the active limb were fixed at only $10 \mathrm{cmH}_{2} \mathrm{O}$, and monitoring to optimise $\mathrm{CO}_{2}$ control was not carried out.

Evidence to date would suggest that a subgroup of patients with severe hypercapnia and sleep disturbance is the most likely to benefit from domiciliary NIPPV. ${ }^{32}$ Further evidence should be forthcoming in the next year from several multicentre European studies of NIPPV versus LTOT-plus-NIPPV which are now in progress.

\section{PAEDIATRIC NIPPV}

Fears that children are unable to tolerate NIPPV have proved groundless. Mask ventilatory support has now been used in children as young as a few weeks of age. There is growing experience in treating children with ventilatory failure due to neuromuscular disorders involving the respiratory muscles such as spinal muscular atrophy (intermediate and type II), muscular dystrophies, myopathies and central hypoventilation disorders. ${ }^{153}$ Children usually present with failure to thrive, recurrent chest infections and/or symptoms of nocturnal hypoventilation. There is no evidence that prophylactic institution of NIPPV before the development of hypercapnia is of value ${ }^{34}$ but once $\mathrm{CO}_{2}$ retention occurs, NIPPV can be lifesaving. CPAP may be helpful in infants and older children with obstructive sleep apnoea due to congenital disorders such as Prader Willi and Treacher-Collins syndrome. ${ }^{35}$ Careful monitoring to ensure control of nocturnal arterial oxygen saturation and endtidal/transcutaneous $\mathrm{CO}_{2}$ is essential.

1 Sullivan CE, Issa FG, Berthon-Jones M, Eves L. Reversal of obstructive sleep apnea by continuous positive pressure applied through the nares Lancet 1981;1:862-5.

2 Chailleux, E. Antadir Obbservatory. Data of fanuary 11996 Trends, Paris:Antadir, 1997.

3 Elliott MW, Aquilina R, Green M, Moxham J, Simonds AK. A comparison of different modes of non-invasive ventilatory support: effects on ventilation and inspiratory muscle effort. Anaes thesia 1994;49:279-83.

4 Younes $M$. Proportional assist ventilation, a new approach to ventilator support. Theory. $A m R e v$ Respir Dis 1992;145:114-20.

5 Schena M, Polese G, Vitacca M, Rossi A, Ambrosino N. Short term effects of nasal proportional assist ventilation (nPAV) on arteproportional assist ventilation (nPAV) on arte-
rial blood gases and dyspnoea in stable hyperrial blood gases and dyspnoea in stable hyp

6 Brochard L, Mancebo J, Wysocki M, et al. Non-

6 Brochard L, Mancebo J, Wysocki M, et al. Noninvasive ventilation for acute exacerbations of chronic pulm

7 Kramer N, Meyer TJ, Meharg J, Cece RD, Hill NS. Randomized prospective trial of noninvasive positive pressure ventilation in acute respiratory failure. Am $\mathcal{7}$ Respir Crit Care Med 1995;151:1799-806.

8 Ambrosino N, Foglio K, Rubini F, Clini E, Nava $S$, Vitacca $M$. Non-invasive mechanical ventilation in acute respiratory failure due to chronic tion in acute respiratory failure due to chronic
obstructive airways disease: correlates for sucobstructive airways disease:
cess. Thorax 1995;50:755-7.

9 Bott J, Carroll MP, Conway JH, et al. Randomised controlled trial of nasal ventilation in domised controlled trial of nasal ventilation in acute ventilatory failure due to chronic obstructive airways disease. Lancet 1993;341:1555-7.

10 Barbe F, Togores B, Rubi M, Pons S, Maimo A Agusti AGN. Non-invasive ventilatory support does not facilitate recovery from acute respiratory failure in chronic obstructive pulmonary disease. Eur Respir f 1996;9:1240-5.

11 Elliott MW, Steven MH, Phillips GD, Branthwaite MA. Non-invasive mechanical ventilation for acute respiratory failure. $B M \mathcal{F} 1990$; 300:358-60.

12 Wysocki M, Tric L, Wolff MA, Gertner J, Millet H, Herman B. Noninvasive pressure support ventilation in patients with acute respiratory ventilation in patients with acut
failure. Chest 1993;103:907-13.

13 Pinto AC, Evangelista T, Carvalho M, Alves MA, Sales Luis ML. Respiratory assistance with a non-invasive ventilator (BiPAP) in MND/ALS a non-invasive ventilator (BiPAP) in MND/ALS patients: survival rates in a contro

14 Shneerson JM. Motor neurone disease. $B M \mathcal{F}$ 1996;313:244-5.
15 Simonds, A.K. Paediatric non-invasive ventilation. In: Simonds AK, ed. Non-invasive respiratory support. London: Chapman \& Hall Medical 1996; pp 102-15.

16 Meduri GU, Cook TR, Turner RE, Cohen M Leeper KV. Noninvasive positive pressure ventilation in status asthmaticus. Chest 1996;110. 767-74.

17 Piper AJ, Parker S, Torzillo PJ, Sullivan CE, Bye PT. Nocturnal nasal IPPV stabilizes patients with cystic fibrosis and hypercapnic respiratory with cystic fibrosis and hyperca
failure. Chest 1992;102:846-50.

18 Hodson ME, Madden BP, Steven MH, Tsang VT, Yacoub MH. Non-invasive mechanical ventilation for cystic fibrosis patients - a potential tilation for cystic fibrosis patients-a potential bridge

19 Philit F, Langevin B, Bertocchi M, Mornex JF, Robert D. Nasal intermittent positive pressure ventilation in 11 patients with obstructive lung disease awaiting lung transplantation. Eur Respir f 1997;10:34s.

20 Chevrolet JC, Jolliet P, Abajo B, Toussi A, Louis $M$. Nasal positive pressure ventilation in patients with acute respiratory failure. Chest 1991 100:775-82.

21 Nava S, Ambrosino N, Vitacca M, Orlando A, Prato M, Rubini F. Randomised prospective study of the use of non-invasive mechanical ventilation (NIMV) in the weaning from invasive mechanical ventilation in severe COPD pamechanical ventilation in severe

22 Simonds AK, Elliott MW. Outcome of domiciliary nasal intermittent positive pressure ventilation in restrictive and obstructive disorders Thorax 1995;50:604-9.

23 Leger P, Bedicam JM, Cornette A, et al. Nasal intermittent positive pressure ventilation. Long term follow-up in patients with severe chronic respiratory insufficiency. Chest 1994;105:100-5.

24 Schonhofer B, Wenzel M, Barchfeld T, Kohler D. Nocturnal mechanical ventilation decreases pulmonary hypertension in chronic respiratory pulmonary hypertension in chro
failure. Eur Respir $\mathcal{f} 1997 ; 10: 35 \mathrm{~s}$.

25 Simonds AK, Fielding S, Muntoni F. Impact of nasal ventilation on survival in hypercapnic Duchenne muscular dystrophy (DMD) paDuchenne muscular dystrophy
tients. Eur Respir 7 1997;10:35s.

26 Medical Research Council Working Party Report . Long term domiciliary oxygen therapy in chronic hypoxic cor pulmonale complicating chronic bronchitis and emphysema. Lancet $1981 ; \mathbf{i}: 681-5$

27 Elliott MW, Simonds AK, Carroll MP, Wedzcha JA, Branthwaite MA. Domiciliary nocturnal nasal intermittent positive pressure ventilation in hypercapnic respiratory failure due to chronic obstructive lung disease: effects on sleep and quality of life. Thorax 1992;47:342-8.

28 Strumpf DA, Millman RP, Carlisle CC, et al. Nocturnal positive-pressure ventilation via nasal mask in patients with severe chronic obstructive pulmonary disease. Am Rev Respir Dis 1991, 144:1234-9.

29 Goldstein RS, De Rosie JA, Avendano MA Dolmage TE. Influence of noninvasive positive pressure ventilation on inspiratory muscles. Chest 1991;99:408-15.

30 Meecham Jones DI, Paul EA, Jones PW, Wedzicha JA. Nasal pressure support ventilation plus oxygen compared to oxygen therapy alone in hypercapnic COPD. Am $\mathcal{F}$ Respir Crit Care Med 1995;152:538-44.

31 Gay PC, Hubmayr RD, Stroetz RW. Efficacy of nocturnal nasal ventilation in stable severe chronic obstructive pulmonary disease during a 3 month controlled trial. Mayo Clin Proc 1996;71:533-42.

32 Wedzicha JA, Meecham Jones DJ. Domiciliary ventilation in chronic obstructive pulmonar disease: where are we? Thorax 1996;51:455-7.

33 Barois A, Estournet-Mathiaud B. Ventilatory support at home in children with spinal muscular atrophies (SMA). Eur Respir Rev 1992;10: 319-22.

34 Raphael J-C, Chevret S, Chastang C, Bouvet F. Randomised trial of preventive nasal ventilation in Duchenne muscular dystrophy. Lancet 1994; 343:1600-4.

35 Waters KA, Everett FM, Bruderer JW, Sullivan CE. Obstructive sleep apnea: the use of nasal CPAP in 80 children. Am $\mathcal{F}$ Respir Crit Care Med 1995;152:780-5.

36 Meduri GU, Abou-Shala N, Fox RC, Jones CB Leeper KV, Wunderlink RG. Non-invasive ventilation in patients with acute hypercapnic respiratory failure. Chest 1991;100:445-54.

37 Vitacca M, Rubini F, Foglio K, Scalvini S, Nava $\mathrm{S}$, Ambrosino N. Non-invasive modalities of positive pressure ventilation improve the outcome of acute exacerbations in COLD patients. Intens Care Med 1993;19:450-5.

38 Fernandez R, Blanch LI, Valles J, Baigorri F Artigas A. Pressure support ventilation via face mask in acute respiratory failure in hypercapnic COPD patients. Intens Care Med 1993;19:45661

39 Brochard L, Isabey D, Piquet J, et al. Reversal of acute exacerbations of chronic obstructive lung disease by inspiratory assistance with a face mask. N Engl f Med 1990;323:1523-30. 